\title{
Um olhar dialético para as mudanças curriculares na formação do enfermeiro*
}

\author{
A dialectical view of curriculum changes in nursing training \\ Una mirada dialéctica hacia los cambios curriculares en la formación del enfermero
}

Cássia Regina Fernandes Biffe Peres ${ }^{1}$, Maria José Sanches Marin ${ }^{1}$, Elaine Cristina lacida Soriano², Maria de Lourdes da Silva Marques Ferreira ${ }^{3}$

Como citar este artigo:

Peres CRFB, Marin MJS, Soriano ECI, Ferreira MLSM. A dialectical view of curriculum changes in nursing training. Rev Esc Enferm USP. 2018;52:e03397. DOI: http://dx.doi.org/10.1590/S1980-220X2017038003397

* Autores convidados, CIAIQ 2016.

${ }^{1}$ Faculdade de Medicina de Marília, Marília, SP, Brasil.

${ }^{2}$ Centro Paula Souza, Escola Técnica Estadual Professor Massuyuki Kawano, Tupã, SP, Brasil.

${ }^{3}$ Universidade Estadual Paulista, Faculdade de Medicina, Botucatu, SP, Brasil.

\begin{abstract}
Objective: To understand the contradictions involved in the process of curriculum reconstruction in the training of nurses, on the professors' perception. Method: Qualitative interpretative study, in which professors of nursing courses from three public and three private institutions were interviewed. The analysis was based on dialectical hermeneutics. Results: 21 professors participated in the study. The proposals of changes are associated with advances and resistances, since the extended view of the health-disease process is opposed to the biological view; the diversification of learning scenarios is confronted with the hegemony of the hospital scenario; the integration of teaching and service faces the inequality of participation of the parties; and integration between the basic and the clinical cycle finds resistance in the knowledge accumulated in each discipline. Conclusion: The contradictions found, although inherent to the change process, indicate that persistence and continuous movement towards curriculum reformulation are necessary.
\end{abstract}

DESCRIPTORS

Education, Nursing; Curriculum; Unified Health System.
Autor correspondente:

Cássia Regina Fernandes Biffe Peres

Av. Maria Fernandes Cavallari, 3150, Apto. 323

CEP 17526-760 - Marília, SP, Brasil

c.r.biffe@gmail.com
Recebido: 06/10/2017

Aprovado: 07/06/2018 


\section{INTRODUÇÃO}

As configurações do mundo atual e seu acelerado processo de modernização científica e tecnológica vêm demandando mudanças no processo de cuidar e de ensinar e, para intervir nessa nova configuração, os profissionais de saúde precisam desenvolver competências para atender às demandas sociais ${ }^{(1)}$.

Frente a esse contexto, importantes orientações foram estabelecidas por meio de políticas públicas no setor da educação e da saúde, compreendendo, respectivamente, a Lei de Diretrizes e Bases da Educação Nacional $(\mathrm{LDB})^{(2)}$ e o Sistema Único de Saúde (SUS) ${ }^{(3)}$.

A partir da LDB, foram elaboradas, para os cursos de enfermagem, as Diretrizes Curriculares Nacionais (DCN), em 2001, as quais propõem a formação de profissionais críticos, reflexivos, inseridos no contexto histórico-social, pautados por princípios éticos e capazes de intervir nos problemas/ situações de saúde da população(4).

O SUS traz um conceito ampliado de saúde. Nele se consideram os diferentes determinantes e condicionantes do processo de saúde-doença, estabelecendo que a atenção deve seguir os princípios da universalidade do acesso, integralidade da assistência, equidade, descentralização, hierarquização e participação social com ênfase na atenção primária ${ }^{(5)}$.

Dessa forma, o modelo de atenção biologicista e fragmentado, até então hegemônico, deve dar lugar a um modelo inovador, que considera os princípios do SUS na lógica da vigilância em saúde e que seja capaz de incorporar práticas de promoção, na busca da integralidade do cuidado. Assim, tem-se colocado, como premente, a formação de profissionais imbuídos de cidadania, capacidade de reflexão crítica e com visão ampliada do processo saúde-doença para transformar a forma de pensar e agir sobre o cuidado em saúde ${ }^{(6)}$.

As ações de mudança devem, então, visar à formação de profissionais comprometidos com a atenção à saúde, capazes de perceber a complexidade que envolve suas práticas. Para isso, mudanças paradigmáticas são necessárias, cabendo às instituições formadoras a reorientação do processo de ensino para o desenvolvimento de competências e habilidades agora exigidas.

$\mathrm{Na}$ formação do enfermeiro no Brasil, após mais de uma década da aprovação das DCN, embora se observem avanços nos projetos pedagógicos e nas metodologias de ensino, muitos desafios ainda necessitam ser superados para conseguir o perfil profissional esperado ${ }^{(7)}$.

Entende-se que os dilemas nos processos de mudanças curriculares são vivenciados tanto nos cursos oferecidos por instituições públicas como por instituições privadas. Estudo de revisão da literatura sobre os cursos de enfermagem quanto aos princípios e diretrizes do SUS revelou que a maioria das pesquisas foi realizada em instituições públicas e nas Regiões Sul e Sudeste do país. Além disso, discute-se que o processo de mudanças tem caminhado entre distintas dificuldades, ainda que os princípios e diretrizes do SUS e novos enfoques na aprendizagem estejam permeando sua construção ${ }^{(8)}$.
Nesta direção, desde 2012, a Associação Brasileira de Enfermagem promove o movimento "Em tempos de Novas DCN”, que busca a mudança do atual quadro da educação em Enfermagem no Brasil. Dentre as mudanças previstas, destacam-se: o reforço à integração teórico-prática, a interdisciplinaridade e a participação dos enfermeiros dos serviços na formação, o estabelecimento das áreas prioritárias de formação de acordo com as características epidemiológicas e necessidades de saúde da população e com os princípios do SUS. Reforça-se ainda, a importância do ensino presencial ${ }^{(9)}$.

É certo que o avanço na formação dos profissionais da saúde exige profundas mudanças. É preciso desvencilhar-se de princípios arraigados no modelo de ensino que, por muitos anos, esteve pautado no método tradicional, bem como no modelo de cuidado centrado em princípios fragmentados, voltados para os aspectos biológicos e para a doença. Esses princípios, apesar da ênfase dada às mudanças, ainda se mantêm no imaginário dos atores envolvidos no processo de ensinar e de cuidar ${ }^{(7)}$.

Assim, tem-se a compreensão de que o processo de mudanças tem ocorrido envolto por contradições entre o que é proposto pelas políticas públicas, o que é conhecido por seus atores e o que é posto pelo contexto institucional.

$\mathrm{Na}$ compreensão do significado de contradição, encontram-se distintas interpretações. As principais delas referem-se às perspectivas da lógica formal e da dialética. A contradição na lógica formal é compreendida como reflexões absolutas e adequadas à realidade objetiva, enquanto para a dialética, a contradição denota a interpenetração de opostos em sua unidade, inexistindo a possibilidade de separação dos opostos. Neste caso, considera-se uma unidade de opostos. Salienta-se que para duas características serem opostas, elas devem ter algo em comum, havendo sua ativa interconexão dentro de um dado fenômeno ou objeto. Assim, a impulsão para as mudanças se constitui em uma dessas unidades de opostos, uma vez que um sistema que passa por isso está se propondo a ser algo que não era antes ${ }^{(10)}$.

$\mathrm{Na}$ compreensão de Hegel e Marx, o mundo evolui devido às tensões internas entre os opostos. Reforça-se que o mérito para avançar nas mudanças está no reconhecimento de ambas as dimensões das contradições ${ }^{(11)}$.

Partindo da compreensão de contradição na lógica dialética e de um processo de formação em franco movimento de mudança, é importante retomar a afirmação de Hegel de que um objeto mutável, ao mesmo tempo, existe em um estado dado e em um estado não dado, e depreender disso que, para haver avanços na formação do enfermeiro, a contradição precisa ser considerada ${ }^{(10)}$.

Frente a isso, tem-se para o presente estudo, o seguinte questionamento: Em quais circunstâncias as contradições vêm permeando o processo de mudanças na formação dos profissionais enfermeiros? O objetivo é compreender as contradições envolvidas no processo de reconstrução curricular a partir da ótica de docentes de cursos de instituições públicas e privadas. 


\section{MÉTODO}

Trata-se de uma pesquisa qualitativa na modalidade interpretativa, realizada por meio de entrevistas com docentes enfermeiros. O campo constitui-se nas Instituições de Ensino Superior (IES) do estado de São Paulo que oferecem cursos de graduação em enfermagem. Segundo dados do Ministério da Educação, em 2013, o estado de São Paulo contava com 178 Cursos de Enfermagem cadastrados em 141 IES, e destes, apenas nove $(4,8 \%)$ eram pertencentes à iniciativa pública.

Para a definição amostral dos cursos de instituições privadas, optou-se por incluir aqueles com nota três ou mais no Sistema Nacional de Avaliação da Educação Superior (SINAES), por se tratar de um processo de avaliação reconhecido. Quando os cursos não atingem tal conceito, já se encontram fora do padrão mínimo estabelecido para um bom funcionamento. Desta forma, do total de 178 cursos de enfermagem de escolas privadas do estado de São Paulo, seis $(3,4 \%)$ contavam com conceito cinco; $20(11,2 \%)$ com conceito quatro; $46(25,8 \%)$ com conceito três; $49(27,5 \%)$ com conceito dois; dois $(1,1 \%)$ com conceito um; $20(11,2 \%)$ sem conceito e $35(19,7 \%)$ sem avaliação ${ }^{(12)}$.

A partir da seleção dos 72 cursos de instituições privadas, com nota três ou mais no SINAES, estabeleceu-se como critério de inclusão estar, no mínimo, com 10 anos de funcionamento, considerando que, para atender às novas diretrizes curriculares, deveriam desenvolver processos de mudanças. Assim, 25 cursos atenderam aos critérios estabelecidos.

Quanto aos cursos de instituições públicas, foi incluída a totalidade deles, ou seja, nove, independentemente do conceito atribuído pelo SINAES, pois as que são reguladas pela Secretaria de Estado não têm a obrigatoriedade de submissão aos critérios de avaliação do Ministério da Educação. Depois de aplicados os critérios de inclusão, realizou-se sorteio de três cursos de instituição pública e três de privada. A intencionalidade de realizar a pesquisa em IES públicas e privadas foi buscar a diversidade organizativa das IES. Depois do sorteio dos cursos, foi realizado contato com o coordenador, para obter a autorização para a realização do estudo. Nos casos em que o coordenador e/ou a instituição não concordaram, foi realizado um novo sorteio, até que se obteve a amostra necessária.

A entrevista foi utilizada como técnica de fonte de informação de dados primários, com perguntas semiestruturadas e abordaram a prática docente no direcionamento do Ministério da Saúde e da Educação na formação de enfermeiros, visando a atender aos princípios e diretrizes do SUS. A população do estudo se constituiu, após a saturação teórica, de 21 entrevistados, docentes de seis cursos de enfermagem do estado de São Paulo, sendo três privados e três públicos. Para a seleção dos docentes, foi solicitada a indicação do coordenador do curso, que forneceu seus e-mails para contato. Quando havia recusa ou falta de disponibilidade para participar, um novo contato era feito, até a obtenção de três a quatro participantes por instituição. As entrevistas foram realizadas em local reservado, de acordo com a disponibilidade do participante, no período de agosto de 2015 a março de 2016, com duração média de 40 minutos, foram gravadas e transcritas na íntegra.
A análise dos dados foi pautada na hermenêutica-dialética, tendo como referência os princípios e diretrizes do $\mathrm{SUS}^{(3)}$ e as Diretrizes Curriculares Nacionais ${ }^{(2)}$ para os cursos de enfermagem. Isso possibilitou a compreensão dos fenômenos em sua complexidade e historicidade, com vistas a evidenciar as contradições inerentes ao processo de desenvolvimento curricular. Para a interpretação, no primeiro momento, fez-se a "ordenação dos dados" pelas entrevistas, o que permitiu a organização de acordo com as questões propostas. Num segundo momento, foi realizada a "classificação dos dados", processo que consistiu em compreender os dados a partir de questionamentos, com base nos fundamentos teóricos. Por meio de leitura exaustiva dos relatos, foram identificadas as estruturas relevantes das falas dos participantes e agrupadas em núcleos de sentido, possibilitando o estabelecimento das categorias empíricas a serem confrontadas com as analíticas, estabelecidas para balizar a investigação e buscar as relações dialéticas entre elas. Por fim, realizou-se a "análise final”, por meio da articulação entre os dados coletados e os referenciais teóricos da pesquisa. Num movimento dialético, considerou-se, especialmente, a contradição para compreender as interfaces do processo de mudanças na formação do enfermeiro de acordo com a Política Nacional de Saúde ${ }^{(13)}$.

Esta pesquisa foi aprovada pelo Comitê de Ética em Pesquisa que envolve Seres Humanos, sob o parecer n. ${ }^{\circ}$ 816.301, de 02/10/2014. Os participantes assinaram o Termo de Consentimento Livre e Esclarecido. Para preservar o anonimato, os participantes foram identificados por "PRO", seguido do número da entrevista, as IES públicas por "P" e as privadas, por "PRI".

\section{RESULTADOS}

Dos 21 entrevistados, a maioria (19; 90,5\%) era mulheres, com idade entre 32 e 59 anos, e a maioria com mais de 50 anos. O tempo de formado variou de nove a 36 anos, e o tempo de trabalho na instituição foi de 2 a 28 anos. Em relação à titulação, cinco $(23,8 \%)$ eram especialistas, sete $(33,3 \%)$ mestres, oito $(38,1 \%)$ doutores e um era livre-docente.

A percepção docente do processo de mudança na formação do enfermeiro fez emergir cinco categorias que representam um movimento dialético em relação ao contexto da Política Nacional de Saúde e às DCN, quais sejam: a proposta de mudanças e a resistência a elas, visão ampliada do processo saúde-doença contrapondo-se à visão biologicista, diversificação do cenário de ensino-aprendizagem e o foco na área hospitalar, integração entre as disciplinas do ciclo básico e clínico e a organização curricular por disciplinas e a integração e a des-integração ensino-serviço.

\section{A PROPOSTA DE MUDANÇAS E A RESISTÊNCIA A ELAS}

Nas falas dos participantes, observa-se que as propostas de mudanças permeiam as resistências. $O$ fato de estarem acostumados com a fragmentação dos conteúdos, das disciplinas e a falta de diversificação dos cenários de atenção tem dificultado a incorporação de uma nova lógica de ensino. 
Compreende-se que a aceitação das mudanças deve ocorrer processualmente, uma vez que, conforme elas vão acontecendo, os atores envolvidos no processo vão verificando seus benefícios. Além disso, com o tempo, os próprios alunos vão provocar as mudanças de atitudes dos professores.

Fica evidente, ainda, que a efetivação do processo de mudanças exige a incorporação de novos saberes e fazeres, o que nem sempre é uma condição fácil, pela própria forma de inserção dos docentes no processo de ensino.

(...) tem pessoas que não entram, mas isso aí todo lugar nós vamos ter: os que não aceitam essas mudanças. No final, eles vão ter que entrar na mudança porque eles estão vendo esses benefícios. Os próprios alunos vão acabar cobrando essa atitude desses professores que querem ainda continuar naquele tradicional, sabe? (PRO1/P2).

As pessoas são muito resistentes às mudanças (...) Muitas vezes, a gente percebe que a resistência à mudança é o medo mesmo do que isso possa trazer como consequência... Eu preciso estudar mais, eu preciso me preparar mais, eu preciso buscar em outros lugares, para quem trabalba numa escola privada, às vezes, um trabalho só não dá. Precisa buscar um outro vínculo e ai choca essa questão de tempo (PRO1/PR1).

\section{VISÃO AMPLIADA DO PROCESSO SAÚDE-DOENÇA CONTRAPONDO-SE À VISÃO BIOLOGICISTA}

Os docentes que participaram do estudo indicam que, para a compressão do processo de saúde e doença, na lógica ampliada, exige-se a aquisição de novos saberes, pois foram formados para trabalhar com a doença e com tecnologias complexas existentes no cenário hospitalar. Além disso, abordam que há necessidade de investimentos na promoção da saúde e na prevenção de doenças, a partir do entendimento de que, no hospital, é menor a possibilidade de aplicação dessa visão ampliada do processo saúde-doença, frente à complexidade exigida para o manuseio da tecnologia. Ressaltam, ainda, que, mesmo no cenário hospitalar, também são necessárias as reflexões para além do determinante biológico do processo de adoecimento.

Como é que a gente transforma (...) como é que a gente trabalha a questão do processo saúdeldoença (...) Essa lógica começa com a nossa transformação, porque nós fomos formadas olhando o processo doença (PRO4/P2).

Eu acredito que a promoção e a prevenção são onde a gente deve investir muito da nossa energia, muito. Até porque o hospital que a gente tem aqui é um hospital de alta complexidade. Exige saber manusear adequadamente equipamentos sofisticados e a doença em si (PRO4/P2).

Essas disciplinas eu dou fundamentalmente no ambiente hospitalar, que é um ambiente que privilegia muito o determinante biológico no processo de saúdeldoença (...) Eu tento mesmo fazer os alunos enxergarem que a doença não é só determinada biologicamente (...) ela tem determinantes de outros tipos (...) Tento também induzir neles o raciocinio clinico para eles perceberem o que tem do ambiente que pode ter provocado (PRO1/P3).
DivERSIFICAÇÃO DO CENÁRIO DE ENSINO-APRENDIZAGEM E O FOCO NA ÁREA HOSPITALAR

Os entrevistados apontam o esforço para diversificar os cenários de ensino-aprendizagem, iniciando a inserção do estudante na comunidade, para que busque conhecer e compreender como as pessoas vivem, lidam com as diversidades, adoecem e morrem. Isso tem acontecido antes da inserção dele em serviços de saúde de maior complexidade, tirando o foco inicial do cuidado hospitalar. No entanto, essa diversificação se coloca numa fase inicial no processo de mudanças curriculares, pois o hospital ainda se mantém como um local forte para a inserção da academia.

(...) maior atividade desde $01^{\circ}$ ano, atividades fora da sala de aula e junto à comunidade. A gente tem conseguido ampliar os periodos de estágio de ensinos clinicos dentro (...) tanto da área hospitalar (...) como da área da Saúde Coletiva (...) porque aqui - hospital é bem forte, a gente tem levado para a rede também (PRO3/P2).

Antes deles irem para o serviço de saúde, eles são inseridos na própria população (...) para entender como é que ela sobrevive, como é que ela se comporta, como é que ela reage frente às influencias e, depois disso, eles começam a ser inseridos nas Unidades, nos Centros de Saúde, nos Centros de Reabilitação, no Centro de Referência para, depois, entenderem a coisa em um nivel mais complexo (PRO2/PRI2).

\section{INTEGRAÇÃO ENTRE AS DISCIPLINAS DO CICLO BÁSICO E CLIINICO E A ORGANIZAÇÃO CURRICULAR POR DISCIPLINAS}

Referindo-se à integração entre as disciplinas, os entrevistados indicam a existência de muitos problemas, bem como a preocupação com a possibilidade de ruptura total com os docentes das cadeiras básicas, a exemplo do que ocorreu em outra instituição em que os próprios enfermeiros tiveram que assumir o ensino desse conteúdo. Fica claro o reconhecimento de que o conteúdo das cadeiras básicas é importante para a formação do profissional. Apesar do diagnóstico referente às necessidades de mudanças, há concordância de que a departamentalização existente na instituição não tem permitido sua construção integrada. A falta de articulação dos conteúdos, fato apontado pelos entrevistados, faz com que o docente da enfermagem tenha que retomar os conteúdos das cadeiras básicas para o desenvolvimento das atividades referentes ao ciclo clínico.

Nós temos muito problema (...) Eu penso que está chegando em um ponto que pode ser igual ao que aconteceu lá em [nome da cidade], em que o pessoal da Enfermagem tentou, tentou, tentou, tentou e não conseguiu. E aí, quem foi dar a Básica? Foram os Enfermeiros (...) mas a gente não quer isso porque (...) o pessoal é bom (PRO 1/P2).

Uma dificuldade grande é a Departamentalização (...) No ano que passou, nós trabalhamos muito para fazer os ajustes curriculares, ouvindo os professores (...) temos um material muito rico para trabalbar, um diagnóstico muito bom (...) Mas na hora de você mudar alguma coisa é muito difícil. Porque as pessoas já estão acostumadas (PRO2/P2). 
Eles têm essas matérias básicas mais no $1^{\circ}$ semestre. Então, por exemplo, quando eu vou trabalhar com eles na Ginecologia e Obstetricia, eu preciso que eles tenham um conhecimento básico de Anatomia, de Fisiologia e (...) não posso dizer que ele é falho, mas por exemplo, eu acabo tendo que resgatar algumas coisas (...) mais básicas dentro da disciplina (...) para que a gente possa conseguir trabalhar (PRO1/PRI 3).

\section{A INTEGRAÇÃO E A DES-INTEGRAÇÃO ENSINO-SERVIÇO}

Pela fala seguinte, constata-se que os participantes do estudo têm a percepção da necessidade de parceria ensino-serviço para que as propostas curriculares possam avançar no que tange aos princípios e diretrizes do SUS. O docente aproxima-se do campo, busca saber as principais necessidades do serviço para apoiar as intervenções e, ao mesmo tempo, realiza o processo de ensinar. No entanto, o planejamento não inclui a participação ativa dos diferentes atores que deveriam estar inseridos no processo.

Nós precisamos formar esse profissional para atender às necessidades da população dentro de um sistema que a gente sabe que não é perfeito, ele só é perfeito no papel. Porque isso implica em parceria verdadeira (...) Eu vou para o estágio da Saúde da Criança em uma Unidade Básica de Saúde. No inicio do ano, quando eles fazem o planejamento da Unidade, eu vou lá falar (...) Tudo o que está programado aí da Saúde da Criança, o que for imediato que não dá para esperar, o pessoal da Saúde Coletiva (...) Então a Gerente da Unidade faz um juntado de RN de Risco, que precisa de visita domiciliar, pra gente ir lá com nosso aluno. Então isso eu chamo de parceria (PRO4/P2).

\section{DISCUSSÃO}

A análise das contradições implícitas nas mudanças curriculares, ocorridas nos cursos de enfermagem de instituições públicas e privadas do estado de São Paulo, com vistas a atender aos princípios e diretrizes da atual Política Nacional de Saúde, a partir da visão de docentes, permite a compreensão de que, como em todo processo de mudanças, ocorrem reações naturais, percebidas por movimentos nomeados de resistência, ou que culminam na mudança propriamente dita.

Assim, corroborando os depoimentos, discute-se as contradições inerentes às mudanças à luz dos pressupostos do método dialético, proposto por Marx, considerando em essência que as mudanças partem da combinação de princípios dialéticos. Essas mudanças ocorrem com arranjo social gerado por tensão entre opostos. Apesar de uma parte resistir, em determinado momento a mudança acontecerá, pois, um arranjo social cede lugar a outro. Essa mudança irá ocorrer continuamente, uma vez que cada negação, ao mesmo tempo, rejeita e apreende uma nova forma. Assim, sempre há possibilidade de culminar em uma nova fase com aspectos positivos ou não ${ }^{(11)}$.

Os participantes do estudo, concordam com essa perspectiva, ao admitirem que as mudanças ocorrem de forma processual, considerando que, para haver mudanças curriculares efetivas, é necessária a incorporação de novos saberes, uma vez que a formação profissional dos docentes fora pautada na fragmentação do cuidado e nos aspectos biológicos. Ressalta-se, então, que a contradição representa o "motor interno do desenvolvimento", e a "racionalidade é o real que se encontra no momento contraditório dos fenômenos provisórios e superáveis"(14).

Referindo-se à contradição em relação à visão ampliada do processo saúde-doença e a visão biologicista, é preciso considerar que, historicamente, diversas concepções explicaram esse processo. O conceito de saúde não é universal, e sim construído no contexto histórico e social de cada época e sociedade, refletindo sua situação social, econômica, política e cultural ${ }^{(15)}$.

$\mathrm{Na}$ atualidade, ainda que a abordagem da determinação social do processo saúde-doença seja reconhecida pela Constituição Federal e, consequentemente, pela Política Nacional de Saúde, o olhar biologicista, fragmentado e centrado na doença ainda permeia fortemente as práticas do cuidado, o que se reflete diretamente na formação do enfermeiro.

$\mathrm{Na}$ Constituição Federal Brasileira, o conceito de saúde resgata a importância das dimensões econômica, social e política na produção da saúde e da doença. À saúde é atribuído o resultado das condições de alimentação, habitação, educação, renda, meio ambiente, trabalho, transporte, emprego, lazer, liberdade, acesso e posse da terra e acesso aos serviços de saúde. Desta forma, a saúde como resultado da organização social e das condições de produção pode acabar gerando grandes desigualdades ${ }^{(16)}$.

Com a finalidade de avançar nesta perspectiva, o Ministério da Saúde lança, em 2009, a Cartilha da Clínica Ampliada, como uma diretriz para a atuação dos profissionais de saúde. Nela, descreve-se que a Clínica Ampliada supõe articulação e diálogo de diferentes saberes dos profissionais, visando à compreensão do processo de saúde e de adoecimento bem como à inclusão dos usuários do sistema de saúde na elaboração do plano de cuidados ${ }^{(17)}$.

Considerando, portanto, a formação do enfermeiro para atender às necessidades do Sistema Único de Saúde, faz-se necessária a ampliação de seu olhar para além da doença, independentemente do nível de atenção em que se encontra, objetivando o cuidado integral das pessoas. Nesse processo de ampliação do olhar, a diversificação dos cenários para além do cuidado hospitalar torna-se necessária para que os momentos do processo de saúde e doença sejam reconhecidos. Assim, o contexto de vida das pessoas precisa ser considerado na sua complexidade e singularidade em qualquer cenário de cuidado.

A diversificação dos cenários de ensino para essa mudança é uma das estratégias de transformação curricular, pois permite aos estudantes vivenciar realidades bem próximas das que ele encontrará em sua vida profissional ${ }^{(18)}$.

Embora seja apontada como diretriz nas DCN desde 2001, a diversificação dos cenários ainda tem sido um desafio atual na formação de enfermeiros, pois a "desopitalização" do processo de ensino-aprendizagem não é tarefa fácil, pela atração dos graduandos às tecnologias específicas deste cenário ${ }^{(19)}$.

Assim, a inserção do estudante em práticas na Atenção Básica e comunidade é considerada potente estratégia para a construção curricular, e atende à proposta das DCN. A diversificação dos cenários deve acontecer durante toda a formação, destacando-se aproximações em séries iniciais como maior possibilidade de formação crítico-reflexiva ${ }^{(20)}$.

As estratégias de integração ensino-serviço possibilitam a aproximação com o mundo real, o das relações com o 
trabalho, o do cuidado e com o social ${ }^{(21)}$. Trata-se do trabalho coletivo, pactuado e integrado de estudantes e professores dos cursos da área da saúde com as equipes e gestores, objetivando a qualidade do cuidado em saúde e a eficiente formação profissional, com desenvolvimento e satisfação dos trabalhadores ${ }^{(22)}$. Ressalta-se, ainda, que este movimento de integração agrega elementos para romper a acomodação do fazer cotidiano de muitos profissionais e traz à tona a responsabilidade do processo coletivo na formação ${ }^{(21)}$.

A integração deve ser articulada para beneficiar ambas as instituições, serviço e ensino, em prol da comunidade, visto que a academia necessita dos cenários para que os estudantes vivenciem a realidade do mundo do trabalho, e essa participação na formação permite aos trabalhadores dos serviços a troca de conhecimentos. Esse compartilhamento de saberes representa oportunidade de melhorias nas instituições, com reflexo na qualidade do cuidado ${ }^{(23)}$.

No entanto, em situações nas quais os interesses são definidos unilateralmente, o sucesso pode ficar comprometido, considerando a importância do constante diálogo entre as partes. Assim, a articulação entre ensino e serviço exige mediações complexas, com construção de projetos coletivos, corresponsabilidade, garantia de diálogo e negociação no micro e macroespaç̧ ${ }^{(24)}$.

Outro importante desafio no processo de mudança na formação do enfermeiro é a difícil integração entre as disciplinas dos ciclos básico e clínico. Ao longo da história, as IES têm organizado seus currículos em disciplinas isoladas, desvinculadas da prática profissional, hipertrofiadas em conteúdo, voltadas para uma formação tecnicista e para especialidades ${ }^{(25)}$. Nessa organização curricular fragmentada, a articulação entre os conteúdos das diferentes disciplinas e a consequente aplicação desses saberes na prática tornam-se pouco exequíveis.

Assim, evidencia-se a necessidade de novas organizações curriculares, com abordagens dialógicas e inserção da escola no mundo do trabalho, que possibilite uma prática reflexiva, valorizando o enfoque "problematizador". Nesse caso, a construção do conhecimento se dá a partir da prática, com estudante e professor sendo sujeitos na produção contextualizada de saberes ${ }^{(26)}$.

Reafirma-se, assim, que o processo de mudanças remete à compreensão das leis da dialética, sendo elas: a passagem da quantidade para a qualidade, a qual indica que as coisas não mudam no mesmo ritmo, pois passam por períodos de lentidão intercalados por períodos de modificações radicais; a interpenetração dos contrários, remetendo ao entrelaçamento dos diferentes aspectos da realidade, de modo que as coisas não podem ser vistas de forma isolada; e a negação da negação, que direciona para o entendimento de que o movimento geral da realidade não é absoluto, pois uma afirmação leva a uma negação, e tanto a afirmação como a negação são superadas, prevalecendo a síntese entre elas ${ }^{(27)}$.

\section{CONCLUSÃO}

Em uma visão dialética do processo de mudanças, em que a contradição é considerada inerente a ele, no presente estudo, foram identificados importantes aspectos que permeiam essas mudanças curriculares de cursos de enfermagem do estado de São Paulo, após mais de uma década da publicação das diretrizes para a formação do enfermeiro em conformidade com os princípios e diretrizes do SUS.

Constatou-se que a necessidade de mudanças permeia as resistências a elas, e que os participantes do estudo reconhecem que essa condição é inerente ao processo, devendo ser superada com o tempo. Além disso, os docentes entrevistados apontam que tais mudanças demandam a incorporação de novos saberes, pois sua formação profissional teve como foco o modelo biologicista, com ênfase em tecnologias complexas.

As contradições também foram evidenciadas na abordagem da necessidade de diversificação do cenário de ensino e aprendizagem, na integração entre ciclo básico e ciclo clínico e entre ensino e serviço. Embora os próprios docentes reconheçam a importância de avançar frente a isso, como importantes atores do processo de mudanças, muitos mostram resistências ou revelam dificuldade em compreender o real significado de tal processo.

Depreende-se que as mudanças curriculares vêm ocorrendo entre avanços, retrocessos e desafios. Muito esforço ainda será necessário para que elas ocorram de fato, visto que envolvem novas formas de pensar e agir em relação ao processo de ensino-aprendizagem e de cuidado.

Por fim, aponta-se como limite do estudo o fato de ele ter sido realizado em seis cursos de enfermagem do estado de São Paulo, o que por certo não representa a totalidade dos cursos existentes no país, especialmente os de outras regiões que apresentam características distintas. No entanto, diante das propostas de mudanças e da responsabilidade das instituições em promover esse processo, com vistas a atender às orientações das políticas de formação dos profissionais de saúde, o presente estudo pode mobilizar reflexões e possibilitar a compreensão do movimento dialético inerente ao processo de mudanças, subsidiando o enfrentamento das contradições.

\section{RESUMO}

Objetivo: Compreender as contradições envolvidas no processo de reconstrução curricular na formação do enfermeiro, pela percepção dos docentes. Método: Estudo qualitativo, na modalidade interpretativa, no qual foram entrevistados docentes de cursos de enfermagem de três instituições públicas e três privadas. A análise ocorreu por meio da hermenêutica-dialética. Resultados: Participaram 21 docentes. Constatou-se que as propostas de mudanças são permeadas por avanços e resistências, uma vez que o olhar ampliado do processo saúde-doença é contraposto à visão biologicista; a diversificação dos cenários de aprendizagem confronta-se com a hegemonia do cenário hospitalar; a integração ensino-serviço esbarra na desigualdade de participação das partes; e a integração básico-clínica encontra resistência no saber acumulado de cada disciplina. Conclusão: As contradições encontradas, embora inerentes ao processo de mudanças, indicam ser necessário persistência e contínuo movimento de reformulação curricular.

\section{DESCRITORES}

Educação em Enfermagem; Currículo; Sistema Único de Saúde. 


\section{RESUMEN}

Objetivo: Comprender las contradicciones involucradas en el proceso de reconstrucción curricular en la formación del enfermero, por la percepción de los docentes. Método: Estudio cualitativo, en la modalidad interpretativa, en el que fueron entrevistados docentes de cursos de enfermería de tres centros públicos y tres privados. El análisis ocurrió mediante la hermenéutica dialéctica. Resultados: Participaron 21 docentes. Se constató que las propuestas de cambios traen consigo avances y resistencias, toda vez que la mirada ampliada del proceso salud-enfermedad se contrapone a la visión biologicista; la diversificación de los entornos de aprendizaje se confronta con la hegemonía del ambiente hospitalario; la integración enseñanza-servicio se topa con la desigualdad de participación de las partes; y la integración básico-clínica encuentra resistencia en el saber acumulado de cada asignatura. Conclusión: Las contradicciones encontradas, aunque inherentes al proceso de cambios, señalan ser necesario persistencia y continuo movimiento de reformulación curricular.

\section{DESCRIPTORES}

Educación en Enfermería; Curriculum; Sistema Único de Salud.

\section{REFERÊNCIAS}

1. Silva RPG, Rodrigues RM. Sistema Único de Saúde e a graduação em enfermagem no Paraná. Rev Bras Enferm [Internet]. 2010 [citado 2017 ago. 15];63(1):66-72. Disponível em: http://www.scielo.br/pdf/reben/v63n1/v63n1a11.pdf

2. Brasil. Lei n. 9.394, de 20 de dezembro de 1996. Estabelece as diretrizes curriculares nacionais [Internet]. Brasília; 1996 [citado 2017 ago. 15]. Disponível em: http://www.planalto.gov.br/CCIVIL_03/Leis/L9394.htm

3. Brasil. Constituição, 1988. Constituição da República Federativa do Brasil. Brasília: Senado; 1988.

4. Brasil. Ministério da Educação. Resolução CNE/CES n. 3, de 7 de novembro de 2001. Institui as Diretrizes Curriculares Nacionais do curso de graduação em Enfermagem [Internet]. Brasília; 2001 [citado 2017 ago. 15]. Disponível em: http://portal.mec.gov.br/cne/arquivos/pdf/CES03.pdf

5. Brasil. Lei n. 8.080, de 19 de setembro de 1990. Dispõe sobre as condições para a promoção, proteção e recuperação da saúde, a organização e o funcionamento dos serviços correspondentes e dá outras providências [Internet]. Brasília; 1990 [citado 2017 ago. 15]. Disponível em: http://www.planalto.gov.br/Ccivil_03/Leis/L8080.htm

6. Gomes AP, Rego S. Transformação da educação médica: é possível formar um novo médico a partir de mudanças no método de ensinoaprendizagem? Rev Bras Educ Méd [Internet]. 2011 [citado 2017 ago. 15];35(4):557-66. Disponível em: http://www.scielo.br/pdf/rbem/ v35n4/a16v35n4.pdf. DOI: http://dx.doi.org/10.1590/S0100-55022011000400016.

7. Soriano ECI, Peres CRFB, Marin MJS, Tonhom SFR. State nursing courses in São Paulo forward the curriculum guidelines. Rev Min Enferm [Internet]. 2015 [cited 2017 Sept 12];19(4):973-9. Available from: http://www.reme.org.br/artigo/detalhes/1053

8. Soriano ECI, Peres CRB, Marin MJS, Tonhom SFR. Nursing courses regarding national curriculum guidelines: comprehensive review. J Nursing UFPE on line [Internet]. 2015 [cited 2016 July 11];9(3):7702-9. Available from: http://www.revista.ufpe.br/revistaenfermagem/ index.php/revista/article/view/6073/pdf_7714

9. Teixeira E. Em tempos de novas Diretrizes Curriculares Nacionais (DCN) para o curso de graduação em enfermagem [editorial]. Rev Enferm UFSM [Internet]. 2017 [citado 25 set. 2017];7(2):iii-iv. Disponível em: https://periodicos.ufsm.br/reufsm/article/view/28859/pdf

10. Marquit E. Contradição na dialética e na lógica formal. Princípios Rev Teór Polít Inf [Internet]. 1996 [citado 2016 mar. 10];43:58-68. Disponível em: http://www.grabois.org.br/cdm/colecao-principios/151718-44623/1996-11-01/contradicoes-na-dialetica-e-na-logica-formal

11. Morgan G. Imagens da organização. São Paulo: Atlas; 2006.

12. Brasil. Ministério da Educação. Instituições de educação superior e cursos cadastrados [Internet]. Brasília; 2016 [citado 2016 mar. 10$].$ Disponível em: http://portal.mec.gov.br/instituicoes-credenciadas

13. Minayo MCS. Trabalho de campo: contexto de observação, interação e descoberta. In: Minayo MCS, organizadora. Pesquisa social: teoria, método e criatividade. $32^{\mathrm{a}}$ ed. Petrópolis: Vozes; 2012. p. 61-78.

14. Egry EY. Saúde coletiva: construindo um novo método em enfermagem. São Paulo: Ícone; 1996.

15. Pereira IC, Oliveira MAC. Atenção primária, promoção da saúde e o Sistema Único de Saúde: um diálogo necessário [Internet]. São Paulo: Escola de Enfermagem da Universidade de São Paulo; 2014 [citado 2017 jul. 20]. Disponível em: http://www.livrosabertos.sibi.usp.br/ portaldelivrosUSP/catalog/view/59/52/247-1

16. Brasil. Ministério da Saúde. Relatório final da $8^{a}$ Conferência Nacional de Saúde [Internet]. Brasília; 1986 [citado 12 mar. 2016 ]. Disponível em: http://conselho.saude.gov.br/biblioteca/relatorios/relatorio_8.pdf

17. Brasil. Ministério da Saúde. HumanizaSUS: clínica ampliada e compartilhada. Brasília: Ministério da Saúde; 2012.

18. Pimentel EC, Vasconcelos MVL, Rodarte RS, Pedrosa CMS, Pimentel FSC. Ensino e aprendizagem em estágio supervisionado: estágio integrado em saúde. Rev Bras Educ Méd [Internet]. 2015 [citado 2017 jul. 24];39(3):352-8. Disponível em: http://www.scielo.br/pdf/rbem/ v39n3/1981-5271-rbem-39-3-0352.pdf

19. Feuerwerker LCM. Além do discurso de mudança na educação médica: processo e resultados. São Paulo: Hucitec; 2002.

20. Silva KL, Sena RR, Silveira MR, Tavares TS, Silva PM. Desafios da formação do enfermeiro no contexto da expansão do ensino superior. Esc Anna Nery [Internet]. 2012 [citado 2017 jul. 11];16(2):380-7. Disponível em: http://www.scielo.br/pdf/ean/v16n2/24.pdf

21. Brehmer LCF, Ramos FRS. Teaching-service integration: implications and roles in experiences of undergraduate courses in nursing. Rev Esc Enferm USP [Internet]. 2014 [cited 2017 July 13];48(1):118-24. Available from: http://www.scielo.br/pdf/reeusp/v48n1/0080-6234reeusp-48-01-118.pdf

22. Albuquerque VS, Gomes AP, Rezende CHA, Sampaio MX, Dias OV, Lugarinho RM. A integração ensino-serviço no contexto dos processos de mudança na formação superior dos profissionais da saúde. Rev Bras Educ Méd [Internet]. 2008 [citado 2016 mar. 20];32(3):356-62. Disponível em: http://www.scielo.br/pdf/rbem/v32n3/v32n3a10.pdf 
23. Baldoino AS, Veras RM. Analysis of service-learning activities adopted in health courses of Federal University of Bahia. Rev Esc Enferm USP [Internet]. 2016 [cited 2017 July 24];50(n.spe):17-23. Available from: http://www.scielo.br/pdf/reeusp/v50nspe/0080-6234-reeusp-50-esp-0017

24. Carvalho SBO, Duarte LR, Guerrero JMA. Parceria ensino e serviço em unidade básica de saúde como cenário de ensino-aprendizagem. Trab Educ Saúde [Internet]. 2015 [citado 2016 ago. 29];13(1):123-44. Disponível em: http://www.scielo.br/pdf/tes/v13n1/1981-7746-tes1981-7746-sip00026.pdf

25. Lazarini CA, Goulart FC. Integração básico-clínica no internato médico: psiquiatria e farmacologia. Rev Bras Educ Med [Internet]. 2013 [citado 2016 fev. 20];37(3):343-9. Disponível em: http://www.scielo.br/pdf/rbem/v37n3/06.pdf

26. Tonhom SFR, Costa MCG, Hamamoto CG, Francisco AM, Moreira HM, Gomes R. Competency-based training in nursing: limits and possibilities. Rev Esc Enferm USP [Internet]. 2014 [cited 2017 July 16];48(spe):213-20. Available from: http://www.scielo.br/pdf/reeusp/ v48nspe2/0080-6234-reeusp-48-nspe2-00213.pdf

27. Konder L. O que é dialética. 28ª ed. São Paulo: Brasiliense; 1998. 